\title{
Optical Properties of Plastic Mulches Affect the Field Temperature Regime
}

\author{
Jay M. Ham, G.J. Kluitenberg, and W.J. Lamont ${ }^{1}$ \\ Department of Agronomy, Throckmorton Hall, Kansas State University, Manhattan KS 66506
}

Additional index words. air temperature, polyethylene, soil solarization, soil temperature, spectral analysis

\begin{abstract}
Research was conducted to determine the optical properties of eight plastic mulches and evaluate their effects on soil, mulch, and air temperatures in the field. Optical properties of the mulches were measured in the laboratory in the shortwave $(0.3$ to $1.1 \mu \mathrm{m})$ and longwave $(2.5$ to $25 \mu \mathrm{m})$ wavebands using a spectroradiometer and Fourier transform infrared spectrophotometer, respectively. Additionally, each mulch was installed on a fine sandy loam soil near Manhattan, Kan. Air and soil temperatures were measured $5 \mathrm{~cm}$ above and $10 \mathrm{~cm}$ below the surface, respectively. Measurements of longwave radiation emitted and reflected from the surface were used to approximate the apparent temperature of the surface. Shortwave transmittance of the mulches ranged from 0.01 to 0.84 , and shortwave reflectance ranged from 0.01 to 0.48 , with the greatest reflectance from white and aluminized mulches. Infrared transmittance ranged from 0.87 for a black photodegradable mulch to 0.09 for aluminized material. Air temperatures at $5 \mathrm{~cm}$ were similar for all mulch treatments, but were typically 3 to $5 \mathrm{C}$ higher than the air at $1.5 \mathrm{~m}$ during the day. Midday soil temperatures were highest beneath mulches with high shortwave absorptance (black plastics) or those with high shortwave transmittance coupled with low longwave transmittance. Apparent surface temperatures approached 70 to $80 \mathrm{C}$ during midday, with the highest temperatures occurring on mulches with high shortwave absorptance. For some mulches, both, shortwave and longwave optical properties of the plastic governed the level of radiative heating. Our results suggest that conduction of heat between the plastic and the soil surface also affects the extent of soil heating in a mulched field.
\end{abstract}

Plastic mulches are used in the cultivation of horticultural crops to modify the soil temperature and moisture regimes, control weeds, deter the immigration of insects, and possibly alter the photobiology of the plant. Plastic mulches primarily affect the field microclimate by modifying the radiation budget of the surface and suppressing soil water evaporation (Liakatas et al., 1986; Tanner, 1974). These microclimate factors strongly affect the soil temperature and soil moisture in the root zone, which, in turn, may influence plant growth and productivity. Many researchers have shown that the phenology, yield, and quality of certain crops can be enhanced by the temperature and moisture aspects of mulching (Bhella, 1988; Maiero et al., 1987; Wien and Minotti, 1988). Others have demonstrated that the quality of radiation reflected from certain mulches can have a direct effect on aboveground plant growth (Decoteau et al., 1988, 1989) or deter the immigration of disease-carrying insects (Greenough et al., 1990). Computer simulation has shown that radiation reflected and emitted from the mulched surface may affect leaf temperature and plant water use (Ham et al., 1991).

The effect of a plastic mulch on soil temperature, surface temperature, and the radiation balance is determined primarily by the optical properties of the material. Mulches may transmit, absorb, or reflect a portion of the incident radiation at each wavelength. For example, a plastic mulch may transmit almost all the radiation at one wavelength, while strongly absorbing or reflecting radiation at another (Loy et al., 1989). Additionally, one must consider shortwave radiation originating from the sun $(0.2$ to

Received for publication 8 June 1992. Accepted for publication 21 Sept. 1992. Contribution no. 92-590-J from the Kansas Agricultural Expt. Sta., Manhattan. We acknowledge T. Demetriades-shah, J. Heilman, R. Gesch, J. Schlup, and Lisheng $\mathrm{Xu}$ for their assistance with the spectral measurements. Mention of a trademark or proprietary product does not constitute a guarantee or warranty of the product by the Kansas Agr. Expt. Sta. and does not imply its approval to the exclusion of othe products that may be suitable. The cost ofpublishing this paper was defrayed in part by the payment of page charges. Under postal regulations, this paper therefore must be hereby marked advertisement solely to indicate this fact.

'Dept. of Horticulture, Forestry, and Recreation Resources.
$1.2 \mu \mathrm{m})$ and long wave radiation originating from terrestrial sources ( 2 to $50 \mu \mathrm{m}$ ). Thus, predicting how a given plastic will influence the field environment requires a complete spectral characterization of the material in the shortwave and longwave bands (Kluitenbergetal., 1991). Such data can then be used in conjunction with a numerical model to study how certain mulches influence soil temperature (Mahrer, 1979; Mahrer et al., 1984). Spectral properties of plastic mulches and their relationship to the field temperature regime have not been documented, although many different types of synthetic mulches are commercially available.

Previous experiments conducted with several mulches showed that differences in optical properties between plastics resulted in large dissimilarities in the apparent temperature of the mulch surface (Ham et al., 1991). These data suggested that subsurface soil and near-surface air temperatures also may be affected by the optical properties of the mulch and indicated the need for a more detailed evaluation of the materials and their effects on the plant environment.

The objectives of this study were to document the optical properties of a variety of plastic mulches in the shortwave and infrared wavebands and experimentally evaluate the effect of the mulches on the field temperature regime. The results will help quantify relationships between mulch optical properties and the extent of soil, air, and surface heating, and allow researchers to gauge the potential impact of different mulches on the crop environment. These data will also be important for developing and verifying numerical models that simulate the temperature regime of a mulched surface.

\section{Materials and Methods}

Research was conducted with eight plastic mulches (Table 1). Plastics included industry standards such as black embossed

Abbreviations: BLCK, black embossed; CLER, clear embossed; DOY, day of year: IRT, infrared transducer; REFL, reflective mulch; SILV, silver reflective; SUNF, selective mulch; WHIT, white on black. 
(BLCK), clear embossed (CLER), and white on black (WHIT). The group included two photodegradable mulches (NT20 and F131) that were black and two reflective mulches (SILV and REFL). The silver reflective mulch (SILV) was a black plastic covered with an aluminum-based coating, while the reflective mulch (REFL) had been impregnated with a reflective compound during manufacturing. Also included was a wavelength selective mulch (SUNF), which is designed to provide maximum heating without transmitting any photosynthetic radiation that would support weed growth. The mulches were composed primarily of polyethylene and were $\approx 32 \mu \mathrm{m}$ thick.

The spectral properties of the eight materials were evaluated in the laboratory using new, unused samples. The total (specular and diffuse) reflectance and transmittance of the mulches were measured from 330 to $1100 \mathrm{~nm}$, in $3 \mathrm{~nm}$ increments, with a LI-1800 spectroradiometer and 1800-12S integrating sphere with illuminator (LI-COR, Lincoln, Neb.). Mean weighted reflectance (p) and transmittance $(\tau)$, in reference to the solar spectrum, were calculated as:

$$
\rho=\int \rho_{\lambda} E_{\lambda} d \lambda+\int E_{\lambda} d \lambda
$$

and

$$
\tau=\int \tau_{\lambda} E_{\lambda} d \lambda+\int E_{\lambda} d \lambda
$$

where $\rho_{\lambda}$ and $\tau_{\lambda}$ represent measured reflectance and transmittance at wavelength $\lambda$, and $E_{\lambda}$ is solar emission intensity at $\lambda$. The emission spectrum was calculated using Planck function at $6000 \mathrm{~K}$ to represent solar h-radiance. Equations 1 and 2 represent average reflectance and transmittance between 0.3 and $1.1 \mu \mathrm{m}$ that has been weighted by the distribution of incident solar radiation in that waveband. Mean weighted optical properties can be multiplied by the total solar energy incident on the plastic to determine the quantity of radiant energy reflected or transmitted. Mean shortwave absorptance $(\alpha)$ was then calculated as a residual $(\alpha=1-\rho-\tau)$.

Direct beam transmittance, $\tau_{\mathrm{ir}}$, of the mulches in the longwave spectrum was measured with a Fourier transform infrared spectrophotometer, FTIR (model Nova Cygni, Mattson, Madison, Wis.). However, radiant emission $\mathrm{E}_{\lambda}$ was computed using a Planck function at $308 \mathrm{~K}$ to represent longwave radiation emitted from terrestrial sources (e.g., soil, sky, plants). Like other integrated optical properties, $\tau_{\text {ir }}$ provides a way to quantify the fraction of longwave radiant energy that will be transmitted through the material.

All eight plastic mulches were installed at the Kansas State Univ. Horticultural Farm, $15 \mathrm{~km}$ south of Manhattan $\left(39.12^{\circ} \mathrm{N}\right.$, $36.35^{\circ} \mathrm{W}, 324 \mathrm{~m}$ above m.s.1.). The soil at the site was a Haynie very fine sandy loam. A predawn rain of $17 \mathrm{~mm}$ moistened the soil profile on the day of mulch installation. Before the plastics were installed, the soil was tilled, and 0.76-m wide raised beds were

Table 1. Name and manufacturer of the mastic mulches.

\begin{tabular}{lll}
\hline \hline Mulch & Name/model & Manufacturer \\
\hline BLCK & Black embossed & Tredegar \\
F131 & F131-photodegradable & Plastigone Technologies \\
NT20 & NT-photodegradable & Consolidated Thermoplastics \\
SUNF & Sunfilm (IRT-76) & A.E.P. Industries \\
REFL & Reflective mulch & A.E.P. Industries \\
S ILV & Silver reflective & PolyAgro Plastic \\
WHIT & White on black & Tredegar \\
CLER & Clear embossed & Tredegar \\
\hline
\end{tabular}

formed with a bed press pan (Kennco Mfg. Co., Ruskin, Fla.). The beds had a height of $16 \mathrm{~cm}$, and the distance between the centers of adjacent beds was $1.52 \mathrm{~m}$. Each plastic mulch was installed in a separate 12.2-m squareplot that was seven beds wide. Mulches were installed with a plastic laying machine (Kennco Mfg.) that stretched the film tightly on the soil surface and left an exposed mulch strip that was $0.76-\mathrm{m}$ wide. A bare soil plot of equal size was also maintained with raised beds with no plastic. This design resulted in eight mulched plots and one bare soil plot that together covered $\approx 0.2$ ha. No crop was planted on the beds, and no planting holes were cut in the plastic.

Subsurface soil temperature, air temperature, and apparent surface temperature of each treatment were measured between 2 July (DOY 183, day of year) and 14 July 1991 (DOY 195). Air temperature was measured continuously in each of the nine plots with three $0.127-\mathrm{mm}$ diameter copper-constantan thermocouples positioned $5 \mathrm{~cm}$ above the surface, near the center of the mulched strip on the center bed. Sensors were shielded from radiation with 2-cm diameter disks suspended above and below the thermojunction. Thermocouples were sampled 50 times every $12 \mathrm{~min}$ using a data collection system composed of data loggers (model 516B, Ominidata International, Logan, Utah) and ice point compensators (model CJ-T, Omega Engineering, Stamford, Conn.). Large plot size ensured that air would flow over three rows of the same mulch before reaching the sensors positioned above the center bed.

Soil temperature in each plot was measured with three hypodermic thermocouple probes positioned $10 \mathrm{~cm}$ below the soil surface in the middle of the mulched bed. Sensors were sampled every 30 min on selected days with a handheld thermocouple thermometer (model HH-23, Omega Engineering). Apparent surface temperature of the mulched bed was measured every 30 to $60 \mathrm{~min}$ on selected days using a handheld infrared transducer (IRT) (model 112, Everest Interscience, Fullerton, Calif.) connected to a data logger (Omnidata International). Mean surface temperature for each treatment was computed from 12 individual measurements on the middle bed in each plot. IRT data were obtained when skies were clear to reduce errors caused by variations in cloud cover. About 6 min was required to sample all treatments during each measurement cycle. IRT measurements were corrected for emissivity and reflected longwave radiation (Fuchs and Tanner, 1966). Emissivities of the mulched surfaces and the bare soil plot were determined from shielded and unshielded IRT surface temperature determinations (Fuchs and Tanner, 1966). Emissivity of the surface is an important parameter, because the longwave radiation emitted from the surface is a function of temperature and emissivity (i.e., Stefan-Boltzmann Law). Because the mulches used in the study could transmit longwave radiation, the IRT was detecting radiation emitted from the plastic and radiation emitted by the soil that was transmitted through the plastic. Thus, all surface temperature measurements and emissivities are apparent rather than actual. However, because the IRT acts as an infrared radiometer rather than a true thermometer, the radiation it detects is a good measure of longwave radiation exiting the surface.

The shortwave albedo of the bare soil plot was measured near midday with a net solarimeter (Radiation Energy Balance Systems, Seattle). A weather station was installed at the site that provided continuous measurements of air temperature at $1.5 \mathrm{~m}$, global irradiance, and wind speed at $2.0 \mathrm{~m}$.

Analysis of variance and mean separation tests were not performed on the data because the treatments and samples were not completely randomized within the experimental area. Large plots were required for each treatment to ensure that the sampling 
location was surrounded by adjacent strips of the same mulch type. That is, spatial randomization was sacrificed to obtain a realistic aerial and belowground microclimate at each sampling location. No obvious gradients in soil texture or other physical properties were evident within the experimental area.

\section{Results and Discussion}

Mulch optical properties. Spectroradiometer readings showed that the plastics represented a wide range of optical properties (Table 2). Shortwave absorptance, a, ranged from near unity for the black plastics to 0.05 for the clear mulch. Reflectance ranged from 0.48 for WHIT to near zero for the black plastics (i.e., BLCK, NT20, F131). Transmittance was $<0.25$ for most mulches, the exceptions being REFL and SUNF, with moderate transmittance, and CLER with a transmittance of 0.84. Thus, almost any combination of shortwave optical properties are available in modern plastics. High reflectance $(r>0.48)$ appeared to be the only optical property that was not represented by at least one of the selected mulches.

Analysis of transmittance in the longwave spectrum also showed that a wide range of optical properties was present (Table 2). The longwave transmittance, $\mathrm{T}_{\text {ir }}$, was $>0.5$ in all the mulches with the exception of SILV, which had a $\tau_{\text {ir }}$ value of $<0.10$. High infrared reflectance of the aluminum coating used for SILV resulted in low $\tau_{\text {ir }}$. Longwave transmittance was highest in the photodegradable mulches (F131 and NT20) and in CLER. Given the potential level of radiant emission from the soil $\left(>600 \mathrm{~W} \cdot \mathrm{m}^{-2}\right)$, longwave optical properties could have a profound effect on the soil temperature regime.

Emissivities, $\varepsilon$, of the mulched surfaces were also influenced by mulch optical properties (Table 2). Because most of the plastics transmitted a large fraction of longwave radiation, $\varepsilon$ for the mulched surfaces were about equal to that of bare soil. However, the low transmittance of SILV resulted in a low $\varepsilon(0.28)$. This value indicates that the mulched surface would absorb only $28 \%$ of incident longwave radiation and also emit only $28 \%$ of the radiation that would be produced by a blackbody at the same temperature.

The shortwave reflectance (albedo) of the bare dry soil was in

Table 2. Optical properties of the plastic mulches. Included are the weighted reflectance $(\rho)$, transmittance $(\tau)$, and absorbtance $(\alpha)$ of the materials between 0.3 and $1.1 \mu \mathrm{m}$ as measured with a spectroradiometer. Also included is the weighted transmittance $\left(\tau_{\text {ii }}\right)$ of each mulch between 2.5 and $25 \mu \mathrm{m}$ as measured by FTIR analysis. Apparent emissivity $(\varepsilon)$ was measured after the mulches were installed in the field.

\begin{tabular}{lccccc}
\hline \hline & \multicolumn{3}{c}{$\begin{array}{c}\text { Shortwave optical } \\
\text { properties }\end{array}$} & & \multicolumn{2}{c}{$\begin{array}{c}\text { Longwave optical } \\
\text { properties }\end{array}$} \\
\cline { 2 - 6 } Mulch & $\rho$ & $\tau$ & $\alpha$ & $\tau_{\mathrm{ir}}$ & $\varepsilon^{\mathrm{z}}$ \\
\hline BLCK & 0.03 & 0.01 & 0.96 & 0.67 & 0.87 \\
F131 & 0.04 & 0.12 & $\mathbf{0 . 8 4}$ & 0.87 & 0.86 \\
NT20 & 0.01 & 0.23 & 0.76 & 0.79 & 0.88 \\
SUNF & 0.12 & 0.37 & 0.51 & 0.70 & 0.85 \\
REFL & 0.23 & 0.50 & 0.27 & 0.63 & 0.79 \\
SILV & 0.39 & 0.01 & 0.60 & 0.09 & 0.28 \\
WHIT & 0.48 & 0.01 & 0.51 & 0.51 & 0.89 \\
CLER & 0.11 & 0.84 & 0.05 & 0.78 & 0.86 \\
Soil & $0.23^{y}$ & & & & 0.88
\end{tabular}

${ }^{\overline{ }}$ Field measurements were influenced by the optical properties of the plastics and the underlying soil surface.

${ }^{y}$ Shortwave albedo of the bare plot when the surface was dry. the middle of the range observed for the plastics (Table 2).

Soil temperature. Temperature regimes of the mulched and bare soil plots were measured over a 13-day period in 1991 that was characterized by high air temperatures and clear skies (Table 3). Several light rains occurred between DOY 190 and DOY 192. Maximum daily soil temperature at $10 \mathrm{~cm}$ differed between mulches, but the range of maximums between all treatments was typically <5C (Table 4). All mulches, except the WHIT plastic, significantly increased soil temperatures in comparison to the bare soil plot. The highest subsurface temperatures were observed beneath BLCK, F131, NT20, and REFL. The black plastics (BLCK, NT20, F131) all had high shortwave absorptance, which indicated that incoming radiation was initially absorbed by the plastic and then transferred to the soil by conduction. Significant conduction at the mulch-soil interface could have occurred in our plots because good contact was maintained between the mulch and soil surface. The high temperatures beneath REFL were unexpected. Examination of its optical properties showed that REFL had a relatively high shortwave transmittance coupled with a relatively low longwave transmittance (Table 2). REFL could have heated the soil by initially transmitting and/or absorbing shortwave radiation, while preventing the loss of emitted radiant energy in the longwave spectrum. A more detailed energy balance analysis of the surface would be required to test the feasibility of this theory.

Clear plastics are normally used to achieve maximum soil temperatures for soil solarization (DeVay, 1991). However, in our study, clear mulch produced maximum daily temperatures that were lower than those produced by black plastics and the REFL mulch, probably also the result of conduction of heat at the soilmulch interface. If the CLER plastic had been placed loosely on the surface, so that an insulating air gap would have been established, then greater heat storage or less heat loss might have occurred. This situation demonstrates that both mulch optical properties and the methodology used to install the plastics can affect the extent of soil heating.

During the last 2 days of the study, a portion of the data acquisition equipment used for air temperature measurement was reconnected to the subsurface thermocouples. The three sensors in each plot were connected in parallel to obtain the average temperature of the bed. The automated data collection system allowed

Table 3. Daily environmental conditions at the experimental site between 2 July (DOY 183) and 14 July 1991 (DOY 195). Data include maximum and minimum air temperature $\left(\mathrm{T}_{\text {air }}\right)$ total global irradiance $\left(\mathrm{R}_{\mathrm{s}}\right)$, average daytime wind speed $(\mathrm{U})$, and rainfall $(\mathrm{R})$.

\begin{tabular}{|c|c|c|c|c|c|}
\hline \multirow[b]{2}{*}{ DOY } & \multicolumn{2}{|c|}{$\mathrm{T}_{\mathrm{air}}{ }^{\mathrm{z}}\left({ }^{\circ} \mathrm{C}\right)$} & \multirow{2}{*}{$\begin{array}{c}\mathbf{R}_{\mathrm{s}} \\
\left(\mathrm{MJ} \cdot \mathrm{m}^{-2}\right)\end{array}$} & \multirow{2}{*}{$\begin{array}{c}\mathrm{U}^{\mathrm{y}} \\
\left(\mathrm{m} \cdot \mathrm{s}^{-1}\right)\end{array}$} & \multirow{2}{*}{$\begin{array}{c}\mathrm{R} \\
(\mathrm{mm})\end{array}$} \\
\hline & Max. & Min. & & & \\
\hline$\overline{183}$ & 33.4 & 20.5 & 20.6 & 1.2 & 1 \\
\hline 184 & 32.7 & 20.2 & 21.7 & 1.3 & \\
\hline 185 & 36.1 & 16.6 & 28.9 & 1.9 & \\
\hline 186 & 39.0 & 19.2 & 28.9 & 2.6 & \\
\hline 187 & 41.8 & 27.2 & 27.2 & 4.0 & \\
\hline 188 & 41.2 & 23.8 & 23.9 & 2.9 & \\
\hline 189 & 32.9 & 22.1 & 23.6 & 3.0 & \\
\hline 190 & 36.3 & 21.2 & 18.0 & 2.9 & 7 \\
\hline 191 & 36.1 & 22.4 & 15.3 & 2.6 & 13 \\
\hline 192 & 32.4 & 21.4 & 22.0 & 1.3 & 10 \\
\hline 193 & 32.8 & 22.0 & 17.3 & 2.3 & \\
\hline 194 & 31.0 & 15.5 & 24.0 & 0.9 & \\
\hline 195 & 31.0 & 15.9 & 28.5 & 1.5 & \\
\hline
\end{tabular}

${ }^{\bar{T}}$ Measured $1.5 \mathrm{~m}$ above the soil surface.

'Measured $2.0 \mathrm{~m}$ above the soil surface. 
continuous diurnal measurements of soil temperature for each plot (Fig. 1). Predawn soil temperatures under most of the mulches were similar (28C) regardless of optical properties. However, predawn temperatures in the bare soil plot were $4 \mathrm{C}$ lower than those in the mulched areas. Soil nighttime temperatures were higher in the mulched plots because the air gap between the mulch and soil reduces convective heat transfer; the plastics trapped a portion of the outgoing longwave radiation emitted from the soil, and the plastic layer prevented evaporative cooling on the mulched beds. WHIT had lower predawn temperatures than the other mulches. Thus, the white plastic appeared to be the only material that could reduce soil heating during the day and maintain that effect through the entire night period. Maximum soil temperatures on DOY 195 occurred near 1700 HR CST, and the ranking among plastics agreed with data in Table 4 . The amplitude of the diurnal temperature waves ranged from $12.5 \mathrm{C}$ for the bare soil plot to $\approx 9 \mathrm{C}$ for the WHIT and CLER mulches.

Surface temperatures. Attempting to measure the surface temperature of a mulched bed with an IRT is difficult because the instrument detects radiation emitted from the plastic and radiation emitted from the soil that is transmitted through the plastic. Thus, data shown hem are not true thermodynamic temperatures of either the mulch or underlying soil, but a composite representation of both surfaces.

The highest apparent surface temperatures $(>84 \mathrm{C})$ were observed on the BLCK plastic, followed closely by the two black photodegradable mulches, NT20 and F131 (Table 5). Thus, the black plastics tended to generate the highest soil and surface temperatures. Although the REFL mulch also produced high subsurface temperatures, it had a much lower surface temperature. The plastic film of REFL apparently remained at a lower temperature despite high underlying subsoil temperatures, possibly because of low absorptance of REFL in the shortwave and longwave spectra (Table 2). The lowest surface temperatures on mulched beds were maintained on WHIT, which had a daily maximum 17C below that of BLCK. The lowest surface temperatures among all treatments were recorded on the bare soil plot. Data from SILV are not shown, because the low emissivity of the surface disallowed adequate correction of data for emissivity and reflected radiation (Ham and Senock, 1992).

Although surface temperatures of mulched beds are difficult to quantify with an IRT, the raw data from the sensor are good measurements of the total longwave radiation emitted and reflected

Table 4. Maximum daily soil temperature at the 10-cm depth in the mulched and bare plots. Data represent the average of three measurement locations within each plot. SE for the treatment means on DOY 193 are provided to demonstrate the precision of the temperature measurements.

\begin{tabular}{|c|c|c|c|c|c|c|c|c|c|}
\hline \multirow[b]{3}{*}{ DOY } & \multicolumn{9}{|c|}{ Subsurface soil temp $\left({ }^{\circ} \mathrm{C}\right)$} \\
\hline & \multicolumn{8}{|c|}{ Mulch } & \multirow[b]{2}{*}{ Bare soi } \\
\hline & $\overline{\mathrm{BLCK}}$ & F131 & NT20 & SUNF & REFL & SILV & WHIT & $\overline{\text { CLER }}$ & \\
\hline$\overline{183}$ & 37.4 & 36.4 & 37.6 & 35.4 & 37.7 & 35.2 & 33.4 & 35.4 & 33.2 \\
\hline 184 & 37.4 & 36.0 & 37.7 & 34.9 & 37.9 & 34.5 & 32.9 & 35.4 & 34.0 \\
\hline 186 & 39.7 & 38.1 & 39.5 & 37.5 & 40.7 & 36.3 & 35.4 & 38.1 & 37.4 \\
\hline 189 & 38.4 & 37.7 & 38.5 & 36.7 & 39.2 & 35.7 & 34.6 & 36.9 & 35.2 \\
\hline 190 & 38.0 & 37.5 & 38.2 & 36.7 & 38.7 & 35.5 & 34.7 & 36.6 & 35.2 \\
\hline 192 & 37.0 & 36.6 & 36.9 & 35.3 & 37.2 & 34.1 & 33.6 & 35.1 & 31.9 \\
\hline 193 & 35.8 & 34.0 & 35.5 & 34.4 & 35.9 & 33.3 & 32.8 & 34.0 & 32.9 \\
\hline $\mathrm{SE}_{\mathrm{DOY} 193}$ & 0.2 & 0.2 & 0.4 & 0.4 & 0.5 & 0.1 & 0.2 & 0.1 & 0.1 \\
\hline Mean & 37.7 & 36.8 & 37.7 & 35.8 & 38.2 & 35.0 & 33.9 & 35.9 & 34.3 \\
\hline
\end{tabular}

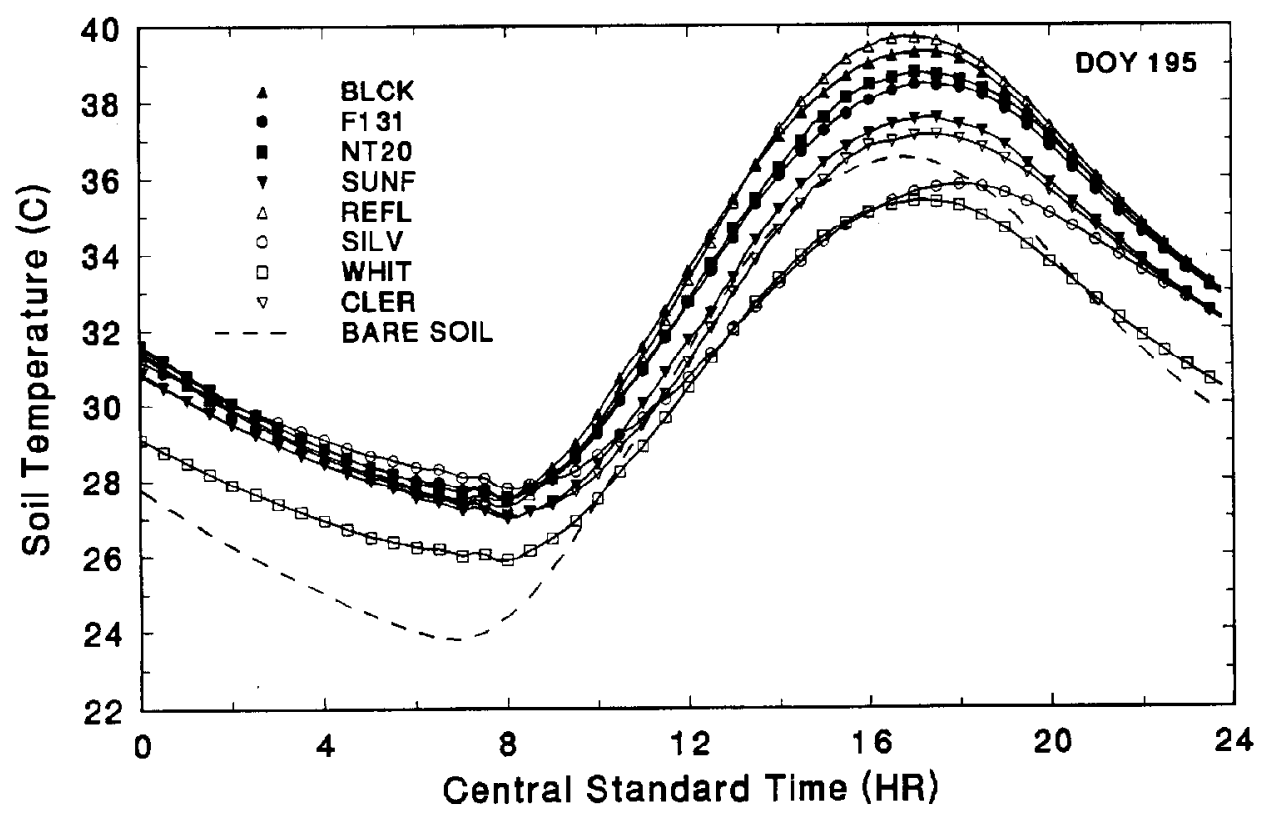

Fig. 1. Diurnal patterns of soil temperature at the 10-cm depth on DOY 195. Data are shown for each of the plastic mulches and the bare soil plot. Skies were clear. 
from the surface. Figure 2 shows the diurnal pattern of outgoing longwave radiation from all nine plots on DOY 186. The greatest quantity of radiation originated from plastics with the highest temperatures (BLCK, F131, NT20). Radiant flux densities from REEL and WHIT were lower and similar in magnitude to that from bare soil. The aluminized SILV emitted and reflected much less radiation, primarily because of the low emissivity of the surface (Table 2). The quantity of outgoing radiation shown in Fig. 2. represents the amount of longwave radiation that would be incident on the underside of an isolated leaf suspended over the mulch. Thus, if a small transplant were inserted into the mulched bed, the quantity of radiation absorbed by the abaxial portion of a leaf could reach $800 \mathrm{~W} \cdot \mathrm{m}^{-2}$, which would be similar in magnitude to shortwave radiation absorbed by the upper surface when exposed to full sun. This fact demonstrates the importance of longwave radiation when considering the effect of mulches on the plant environment.

Near-surface air temperature. Although IRT measurements showed that distinct differences occurred in apparent surface temperature, at $5 \mathrm{~cm}$ above the surface air temperatures were similar for all treatments. Turbulent mixing over the plots apparently was sufficient to dissipate any high temperature plumes originating from the mulched beds. Our data suggest that the air



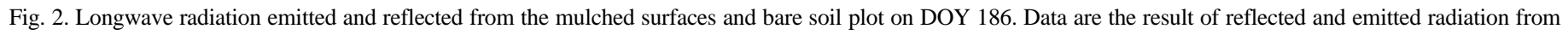
the plastic and underlying soil surface. Values represent the quantity of longwave radiation that would be incident on the underside of a leaf if it were suspended over the mulches.

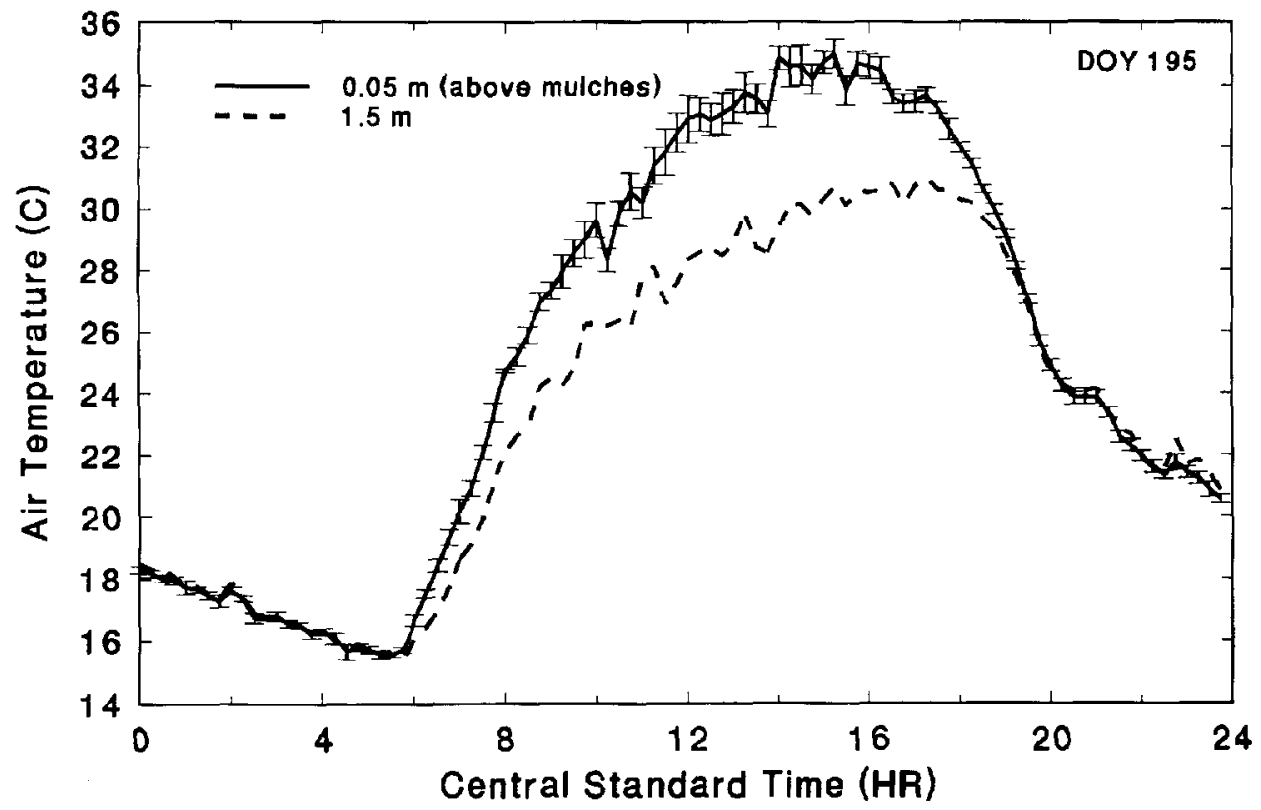

Fig. 3. Diural patterns of air temperature on DOY 195 measured immediately above the mulches $(0.05 \mathrm{~m})$ and at screen height (1.5 m). The 0.05 -m data represent the average of measurements collected above all eight mulch types. Vertical bars represent \pm 1 SE. 
Table 5. Maximum apparent surface temperature of the mulched surfaces and the bare soil as determined by an IRT. Temperatures represent the average of four measurement locations within each plot. Reported temperatures are the result of radiation emitted from the plastic and underlying soil, and thus, do not depict the actual temperature of the plastic surface. SE for the treatment means on DOY 193 are provided to demonstrate the precision of the temperature measurements.

\begin{tabular}{|c|c|c|c|c|c|c|c|c|}
\hline \multirow[b]{3}{*}{ DOY } & \multicolumn{8}{|c|}{ Surface temp $\left({ }^{\circ} \mathrm{C}\right)$} \\
\hline & \multicolumn{7}{|c|}{ Apparent mulch temp } & \multirow[b]{2}{*}{ Bare soi } \\
\hline & BLCK & F131 & NT20 & SUNF & REFL & WHIT & CLER & \\
\hline$\overline{183}$ & 74.8 & 70.0 & 70.0 & 61.6 & 61.2 & 56.3 & 63.2 & 47.1 \\
\hline 184 & 79.3 & 74.1 & 71.9 & 66.2 & 62.2 & 62.7 & 66.9 & 55.6 \\
\hline 186 & 78.1 & 76.6 & 75.7 & 68.4 & 67.4 & 64.6 & 72.7 & 62.3 \\
\hline 187 & 78.0 & 73.0 & 75.5 & 68.0 & 67.6 & 61.5 & 73.1 & 61.7 \\
\hline 188 & 84.6 & 81.1 & 78.2 & 71.9 & 70.1 & 67.6 & 76.0 & 66.2 \\
\hline 189 & 71.2 & 67.1 & 68.2 & 62.3 & 58.1 & 54.2 & 63.1 & 53.6 \\
\hline 190 & 79.4 & 72.8 & 73.7 & 66.9 & 63.6 & 62.6 & 68.5 & 60.7 \\
\hline 191 & 77.9 & 73.3 & 71.0 & 67.4 & 65.4 & 61.4 & 69.9 & 47.6 \\
\hline 192 & 89.2 & 81.1 & 78.3 & 71.5 & 71.1 & 64.7 & 73.1 & 38.5 \\
\hline 193 & 57.9 & 56.3 & 57.9 & 52.3 & 51.5 & 46.9 & 53.0 & 42.0 \\
\hline $\mathrm{SE}_{\mathrm{DOY} 193}$ & 0.9 & 0.8 & 0.7 & 0.6 & 0.3 & 0.5 & 0.4 & 0.5 \\
\hline Mean & 77.0 & 72.5 & 72.1 & 65.7 & 63.9 & 60.1 & 68.0 & 53.5 \\
\hline
\end{tabular}

temperature profile at heights $>5 \mathrm{~cm}$ can be considered independent of mulch optical properties. However, if mulches were installed so that they covered a larger fraction of the surface, then the effect of mulches on air temperature should be re-evaluated.

Air near the mulched surfaces was typically much warmer than air at screen height (1.5 m) (Fig. 3; DOY 195). The air next to the mulches was 4 to $5 \mathrm{C}$ higher than air at $1.5 \mathrm{~m}$ during the day, whereas air temperatures were similar at night. During certain portions of the study, the nighttime air was 1 to $2 \mathrm{C}$ higher near the mulches than at $1.5 \mathrm{~m}$. After a day of strong solar heating, heat from lower depths within the profile moves back toward the surface at night causing the temperature of the surface to be warmer than the air (Oke, 1987). Convective heat flux from the surface then increases the temperature of the air adjacent to the mulch surface.

In summary, photometric analysis of plastic mulches in shortwave and longwave spectrums demonstrated that a wide range of optical properties exists in modem agricultural plastics. Field experiments showed that subsoil and surface temperatures of mulched beds were affected by the optical characteristics of the mulch. However, our experiments were conducted without a crop to maximize solar irradiance on the surface and, thus, intensify the effect of mulch optical properties. Shading of the bed by the developing crop canopy probably would moderate differences between mulches, as well as the effect of mulching in general. Nevertheless, data reported here provide background information that can be used to develop and verify numerical models that simulate the field temperature regime under plastic mulch culture. These models can then be used to evaluate the cumulative effects of mulch properties, the plant canopy, drip irrigation, and other factors on crop productivity.

\section{Literature Cited}

Bhella, H.S. 1988. Tomato response to trickle irrigation and black polyethylene mulch. J. Amer. Soc. Hort. Sci. 113:543-546.

Decoteau, D.R., M.J. Kasperbauer, D.D. Daniels, and P.G. Hunt. 1988.
Plastic mulch color effects on reflected light and tomato plant growth. Scientia Hort. 34:169-175.

Decoteau, D.R., M.J. Kasperbauer, and P.G. Hunt. 1989. Mulch surface color affects yield of fresh-market tomatoes. J. Amer. Soc. Hort. Sci. 114:216-219.

DeVay, J.E. 1991. Historical review and principles of soil solarization, p. 1-15. In: J.E. DeVay, J.J. Stapleton, and C.L. Elmore (eds.). Soil Solarization. FAO Plant Production Paper 109. Rome.

Fuchs, M. and C.B. Tanner. 1966. Infrared thermometry of vegetation. Agron. J. 58:597-601.

Greenough, D.R., L.L. Black, and W.P. Bond. 1990. Aluminum-surfaced mulch: An approach to the control of tomato spotted wilt virus in solanaceous crops. Plant Dis. 74:805-808.

Ham, J.M., G.J. Kluitenberg, and W.J. Lamont. 1991. Potential impact of plastic mulches on the aboveground plant environment. Proc. Natl. Agr. Plastics Congr. 23:63-69.

Ham, J.M. and R.S. Senock. 1992. On the measurement of soil surface temperature. Soil Sci. Soc. Amer. J. 56:370-377.

Kluitenberg, G.J., J.M. Ham, and W.J. Lamont. 1991. Effects of aging on the optical properties of plastic mulches. Proc. Natl. Agr. Plastics Congr. 23:149-154.

Liakatas, A., J.A. Clark, and J.L. Monteith. 1986. Measurements of the heat balance under plastic mulches. Part I. Radiation balance and soil heat flux. Agr. For. Meteorol. 36:227-239.

Loy, B., J. Lindstrom, S. Gordon, D. Rudd, and O. Wells. 1989. Theory and development of wavelength selective mulches. Proc. Natl. Agr. Plastics Congr. 21:193-197.

Mahrer, Y. 1979. Prediction of soil temperatures of a soil mulched with transparent polyethylene. J. Applied Meteorol. 18:1263-1267.

Mahrer, Y., O. Naot, E. Rawitz, and J. Katan. 1984. Temperature and moisture regimes in soils mulched with transparent polyethylene. Soil Sci. Soc. Amer. J. 48:362-367.

Maiero, M., F.D. Schales, and T.J. Ng. 1987. Genotype and plastic mulch effects on earliness, fruit characteristics, and yield in muskmelon. HortScience 22:945-946.

Oke, T.R. 1987. Boundary layer climates. 2nd ed. Methuen, New York. Tanner, C.B. 1974. Microclimatic modification: Basic Concepts. HortScience 9:555-560.

Wien, H.C. and P.L. Minotti. 1988. Increasing yield of tomatoes with plastic mulch and apex removal. J. Amer. Soc. Hort. Sci. 113:342-347. 